\title{
Trabalhonecessário
}

Issn: 1808 - 799X

ano 13 , número $20-2015$

\section{TRABALHO E EDUCAÇÃO COMO PAUTA DO GT TRABALHO E EDUCAÇÃO DA ANPED. ALGUMAS CONSIDERAÇÕES SOBRE O CAMPO DE PESQUISA ${ }^{1}$}

Carmen Sylvia Vidigal Moraes ${ }^{2}$

\section{Resumo}

Tendo como ponto de partida estudos desenvolvidos em minha trajetória de pesquisa, o texto propõe introduzir algumas reflexões sobre os desafios teóricos presentes na relação trabalho e educação e as dificuldades na constituição do referido domínio de conhecimento. Pretende, também, analisar a pertinência e contribuição deste debate para o desenvolvimento de políticas públicas relativas à conformação do ensino médio e, em particular, do ensino médio integrado. Com esses objetivos, a partir de uma leitura crítica das Teorias da Reprodução propiciada pelas contribuições de H. Lefebvre, P. Naville e L. Tanguy, entre outros, retoma algumas formulações sobre a escola e a educação profissional, para, na sequência, discutir a proposta de educação unitária na obra de Gramsci e suas implicações à organização do ensino médio.

Palavras-chave: educação e trabalho, ensino médio integrado, educação profissional.

\footnotetext{
${ }^{1}$ Texto apresentado no "II INTERCRÍTICA -Intercâmbio Nacional dos Núcleos de Pesquisa em Trabalho e Educação", realizado na Universidade Federal do Pará, em agosto de 2014.

2 FEUSP.
} 


\title{
Trabalhonecessário
}

Issn: 1808 - 799X

ano 13 , número $20-2015$

\begin{abstract}
Taking as its starting point the studies developed in my career of search, the text proposes to introduce some thoughts on the theoretical challenges present in the relation of work and education, and difficulties in the constitution of that knowledge domain. It also intends to examine the relevance and contributions of this debate for the development of public policies related to high school conformation and, in particular, the integrated high school. With these objectives, from a critical reading of Reproduction Theories made possible by the contributions of $\mathrm{H}$. Lefebvre, $\mathrm{P}$. Naville and L. Tanguy, among others, it takes up some formulations about the school and vocational education, for, in sequence, discuss the proposed unitary education in Gramsci's work and its implications for high school organization.
\end{abstract}

Keywords: education and work, integrated high school, vocational education.

\begin{abstract}
"Traiter des rapports entre la formation profissionnelle et l'école, c'est aborder tous les aspects de ce qu'on se désigne du terme général d'éducation; c'est toucher aux questions multiples du dévéloppement de l'enfant, des conditions de l'acquisition de connaissances génerales et particulières, de la structure des activités professionnelles et des métiers; c'est implicitement se prononcer sur des principes pédagogiques, sur des concepcions économiques et sociales."
\end{abstract}

(Pierre Naville, La formation professionnelle et l'école) 


\section{Trabalhonecessário}

Issn: $1808-799 X$

ano 13 , número $20-2015$

\section{Introdução}

Na temática que nos foi proposta desenvolver, "Trabalho e Educação como pauta do GT Trabalho e Educação", a preocupação principal indicada consiste em refletirmos sobre as contribuições do nosso grupo de pesquisa à análise dos desafios teóricos presentes na relação trabalho e educação, e a pertinência desses fundamentos teóricos para o desenvolvimento de políticas públicas democráticas que possibilitem, no âmbito da escola básica pública, a construção de um ensino médio de qualidade social, que atenda às necessidades das classes trabalhadoras. A partir do recorte mencionado, e levando em conta os objetivos de sugerir alguns

caminhos possíveis nesse "diálogo entre pesquisadores de pós-graduação e educadores da escola básica" (Kein, L. 2011, p. 9), organizei a exposição de maneira a apresentar, de modo sucinto e quase esquemático, algumas reflexões teóricas que venho desenvolvendo em minha trajetória de pesquisa, as quais - do meu ponto de vista - podem contribuir para fecundar o debate entre nós a respeito das preocupações anunciadas sobre a conformação do ensino médio, e, em particular, do ensino médio integrado.

\section{O Campo de pesquisa Trabalho e Educação: um breve histórico de sua constituição ${ }^{3}$}

Nessa direção, em primeiro lugar, tornam-se necessárias algumas digressões sobre os desafios na constituição do campo de pesquisa Trabalho e Educação.

Embora as pesquisas iniciais sejam mais antigas, pode-se afirmar que é a partir dos anos 1950 que essa área de investigação, nomeada pelos pesquisadores como o das relações ou "vínculos" entre educação e economia, entre formação e

\footnotetext{
${ }^{3} \mathrm{O}$ artigo constitui uma síntese de pesquisas e trabalhos realizados pela autora, apresentados em textos publicados ou não: Moraes, C.S.V., 1999, 2002, 2005, 2012a, 2012b.
}

TrabalhoNecessário - www.uff.br/trabalhonecessario; Ano 13, № 20/2015. 


\section{Trabalhonecessário}

Issn: $1808-799 X$

ano 13 , número $20-2015$

emprego, ou entre "sistema educativo e sistema produtivo", constituiu-se em diferentes países. Esse domínio de pesquisa é bastante amplo, na medida em que propõe relacionar um conjunto de mudanças - desde as mudanças técnicas na produção e na organização do trabalho até as relativas à definição das qualificações e à transmissão de saberes -, o que pressupõe necessariamente o esforço de uma abordagem multidisciplinar - da história e sociologia da educação, da economia e da sociologia do trabalho (Moraes, 2000).

A literatura sobre o "estado da arte" deste campo de investigação vem assinalando que um dos principais desafios da área consiste em integrar conhecimentos que se desenvolvem de forma isolada nas instituições acadêmicas de ensino e pesquisa, como é o caso da economia, da sociologia do trabalho, da sociologia e da história da educação (Tanguy.L.; Marry, C., 1986)

A separação entre as disciplinas tende a ser acompanhada, nos diferentes países, por uma divisão institucional da pesquisa, indicativa - ao mesmo tempo das limitações analíticas que as orientações teóricas predominantes no campo são portadoras. A coexistência de abordagens separadas em relação às instâncias de educação e às instâncias de produção, originária da dualidade institucional, orienta a atual divisão do trabalho na pesquisa e constitui obstáculo considerável à construção do conhecimento, cujo objeto tende a permanecer "reduzido a estes dois termos- trabalho e educação - pensados separadamente" (Tanguy, 1996, p. 107-8).

Um outro importante desafio comumente apontado é o de o campo de pesquisa não ser construído prioritariamente pelas disciplinas acadêmicas, mas a partir de diferentes demandas sociais originárias tanto da administração estatal, quanto das empresas e de outros grupos sociais, organizações profissionais e sindicais. A tensão entre as diferentes lógicas presentes no debate social, entre a "lógica administrativa" e a "lógica científica", irá se traduzir na permanente instabilidade de seu objeto de pesquisa e na diversidade das formas de abordagem ou de referencias teóricos, promovendo maior 


\section{Trabalhonecessário}

Issn: $1808-799 X$

ano 13 , número $20-2015$

complexidade/dificuldade à produção do conhecimento na área (Jobert. Marry, Tanguy, 1995).

No que diz respeito às limitações analíticas a serem enfrentadas, observase, de um lado, as tendências reducionistas das análises econômicas da educação, desenvolvidas no âmbito da Teoria do Capital Humano, de cunho marginalista, que apreendem a educação basicamente como fator de produção, e, de outro lado, os limites apresentados pela chamada sociologia da educação, que se constituiu - em diferentes países - como ramo autônomo da sociologia na década de 1960.

Transformada em uma sociologia da escola, esta sociologia da educação tem contribuído para naturalizar a categoria "ensino" que se realiza sob uma forma escolar nas modernas sociedades ocidentais (Naville, 1948; Tanguy, 1986). No

Brasil, boa parte da expansão desta disciplina processou-se às expensas da mesma "retração temática" (Candido, A. 1972), e seu campo de reflexão tende progressivamente a minimizar ou a excluir pesquisas sobre as relações entre educação e trabalho, sobre o ensino profissional ou técnico (Moraes, 2005, 2012b).

Por fim, os estudos da sociologia do trabalho, após seu desenvolvimento inicial nos anos 1950, particularmente na França (Naville ,1945, 1948, 1956, 1959); Friedman, 1950; M. Guilbert e V. Isambert-Jamati, 1958, 1961), dirigido ao estudo das relações entre o desenvolvimento do ensino profissional e a organização hierárquica do trabalho, assumiu desenvolvimento próprio, separado da vertente educacional. Hoje, suas análises afastaram-se das questões da formação da força de trabalho e priorizam o tratamento das relações entre formação e emprego no âmbito do mercado de trabalho ou na empresa, na perspectiva do uso da força de trabalho e, portanto, de sua qualificação (Tanguy, 1986; Moraes, 1999).

O fortalecimento das ideologias da democratização e das lutas contra as desigualdades sociais nos anos 1950 - 1960 contribuiu para orientar as políticas educacionais de Estados europeus desenvolvidos recém-saídos da segunda guerra mundial. Na França, por exemplo, o "dispositivo escola única pública", implementado entre 1959 e 1963, levou à superação da dicotomia entre a formação 


\section{Trabalhonecessário}

Issn: $1808-799 X$

ano 13 , número $20-2015$

de uma elite letrada e o processo de alfabetização de massa, institucionalizando-se "um terceiro regime histórico, o da escolarização (de massa)" por meio da organização de um contínuo de níveis e modalidades escolares ampliadas até o ensino superior (Terrail e Poullaouec, 2004, p.165).

Tais circunstâncias políticas contribuíram, por um lado, para cristalizar concepções liberais sobre a escola, vista como instituição voltada para a promoção/mobilidade social, e, por outro lado, deram origem a novos questionamentos presentes em uma literatura sociológica que se propõe a analisar as relações entre desigualdades de acesso à educação e desigualdades sociais. As teorias da reprodução cultural, formuladas por Pierre Bourdieu e Jean Claude Passeron (1964, 1970), surgem na França ao lado de outras, de inspiração marxista, notadamente as análises de Louis Althusser (1970), Christian Baudelot e Roger Establet (1971), e Nicos Poulantzas (1974); e nos Estados Unidos, as de J. Bowles e H. Gintis (1976).

Apesar das divergências epistemológicas existentes entre estas correntes de pensamento, sua principal característica foi "a busca de determinantes estruturais do sistema de ensino, percebido em termos da funcionalidade ou da estrutura dos diversos aparelhos" (Cunha Neves et al., 1983, p.58).

Se no âmbito da sociologia da educação havia o predomínio das abordagens "reprodutivistas", instaurando entre muitos pesquisadores "descrédito e desconfiança em relação à instituição escolar" (Gouveia, 1985, p. 74) e um vazio incômodo no que se refere ao ensino técnico e à formação profissional ${ }^{4}$, no campo das análises econômicas a denominada teoria do "capital humano" assumia, no Brasil, o estatuto de "economia da educação" nos cursos de graduação de pedagogia e orientava, nos governos militares, um número significativo de estudos

\footnotetext{
${ }^{4}$. Constitui exceção o trabalho de Luiz Antonio Cunha (1977) sobre a reforma do ensino médio (lei 5672, de 1971), que implantou a profissionalização compulsória no denominado ensino de segundo grau.
}

TrabalhoNecessário - www.uff.br/trabalhonecessario; Ano 13, № 20/2015. 
Issn: 1808 - 799X

ano 13 , número $20-2015$

e pesquisas oficiais que precediam ou avaliavam as reformas educacionais justificando-as ${ }^{5}$.

A teoria do capital humano foi formulada nos finais da década de 1950, nos EUA, por economistas da escola de Chicago (Shultz, 1973; Becker, Mince, 1964), em um programa de investigação cujo propósito explícito era demonstrar a superioridade do mercado e da iniciativa privada, assim como legitimar as diferenças salariais existentes em todas as economias capitalistas. Situada no corpo teórico neoclássico, essa teoria está orientada para negar a existência de classes sociais, a afirmar que todos os homens são capitalistas porque proprietários de capital - meios de produção e capital humano (Recio, A., 1997, p. 33). Tal como o capital físico, o capital humano pode ser valorizado por meio de inversões que os indivíduos fazem em sua própria formação. Sua hipótese básica é a de que os gastos em educação aumentam a produtividade individual das pessoas, e, portanto, os seus rendimentos, gerando a distribuição da renda e promovendo o desenvolvimento econômico e social.

Ao lado das numerosas adesões, surgem novas análises de orientação marxista. Além da contribuição dos economistas radicais norte-americanos (Carnoy e Levin, 1980), outros trabalhos, tanto no campo da sociologia como da economia (Lanay, 1979; Lautier, B. e Tortajada, E., 1978; Sarup, M. 1980), vieram subsidiar as críticas a essa teoria. No Brasil, constituíram referências importantes a produção pioneira de Geraldo Bastos Silva $(1959,1965)$ e, em particular, a de Luiz Pereira (1963, 1965, 1974). Na antologia de estudos sobre sociologia da educação, organizada por Pereira e Foracchi em 1963, os propósitos "de delimitação rigorosa do campo a investigar" incluem uma seção destinada a

\footnotetext{
5. Mario H. Simonsen (1969,p. 60), na época presidente do Mobral do governo Médici, ao explicitar os mecanismos destinados a diminuir a desigualdade social no país, sintetiza de forma clara o pensamento governamental da época: "A primeira dessas medidas consiste em alargar o sistema educacional do país de modo a maximizar a democratização de oportunidades. As grandes diferenças de renda resultam menos da falta de mobilidade social do que das desigualdades do padrão educacional. A ampliação da rede de ensino fundamental gratuito, o aumento acelerado das vagas na universidade são fatores que proverão a médio prazo um reajuste entre oferta e procura no mercado de trabalho, contribuindo para uma diminuição do hiato das rendas individuais e para o desenvolvimento de uma sociedade equitativa do ponto de vista distributivo".
}

TrabalhoNecessário - www.uff.br/trabalhonecessario; Ano 13, № 20/2015. 


\section{Trabalhonecessário}

Issn: 1808 - 799X

ano 13 , número $20-2015$

debater a problemática "das relações entre educação e desenvolvimento econômico-social" situada "na perspectiva do mundo sub-desenvolvido" ( p.359), com a inclusão de autores brasileiros como Anísio Teixeira, Celso Furtado e Florestan Fernandes; de latino-americanos, como Victor Urquidi, e do sueco Gunnar $\mathrm{Myrdal}^{6}$, voltados para 0 debate do conceito sociológico de desenvolvimento.

$\mathrm{Na}$ introdução ao tema, afirmando a necessidade de encarar-se a educação (entendida como processo social global e não apenas na sua forma escolarizada) "sob novo ângulo" e de "o papel do sociólogo ser redefinido em termos de maior amplitude, responsabilidade e audácia", Pereira e Foracchi (1963, p.359) enfatizam "que educação e desenvolvimento não devem ser pensados como processos independentes, que só se associam por imposições das circunstâncias históricas do presente". E argumentam:

embora o assunto em si pareça moderno e atual, o progresso social jamais deixou de apresentar definidas dimensões educativas. Se isso não tivesse acontecido, não poderíamos sequer compreender o significado da educação no mundo moderno, ou seja, seu fator de reconstrução social.

Após o golpe militar e findo o período das esperanças desenvolvimentistas - no estudo "Trabalho e desenvolvimento no Brasil", de 1965, ao "situar a qualificação do trabalho na expansão e consolidação do capitalismo na sociedade brasileira contemporânea", Luiz Pereira define as "relações dinâmicas entre instituições escolares e estruturas sociais inclusivas", como a problemática central do pensamento pedagógico brasileiro, formulando a hipótese de que no processo

6. Myrdal, Secretário Executivo da Comissão Econômica para a Europa da ONU (de 1947 a 1956), foi também Ministro do Comércio da Suécia. Autor de vários livros, um de seus trabalhos "Teoria Econômica e Regiões Subdesenvolvidas", publicado em 1956, vai ser traduzido para o português em 1960 sob os auspícios do Instituto Superior de Estudos Brasileiros/ISEB. Sua concepção sobre a necessidade da intervenção do Estado na superação do subdesenvolvimento e construção da sociedade do bem-estar, o realce que atribui aos fatores políticos na dinâmica social de vários países, parece ter fornecido - segundo Mantega (1985:53-7) -, pistas para análises futuras centradas na "dinâmica interna" ou na luta de classes, como foi o caso - por exemplo - de Celso Furtado. 


\section{Trabalhonecessário}

Issn: 1808 - 799X

ano 13 , número $20-2015$

crescente de burocratização e racionalização da organização escolar (em contraposição ao tradicionalista), a atuação do Estado, de empresários e educadores tendia "a uma instrumentalização cada vez maior das instituições escolares". A economia da educação consistia na teorização dessa instrumentalização, "preocupada com a rentabilidade dos dispêndios realizados ou realizáveis com a educação", que aparece, então, concebida como "instrumento de produção do 'capital humano', as escolas como empresas ou 'locii' dessa produção". O "enfoque, tratamento, conclusões e recomendações" acerca das relações entre educação e subdesenvolvimento-desenvolvimento

encontram-se sempre na linha da 'economia da educação': não se cuida dos homens, mas da força de trabalho; não se trata da constituição de homens historicamente determinados, mas da elaboração de um fator de produção necessário - força de trabalho nos vários níveis e tipos de qualificação técnica. E, assim, reencontramos o tecnicismo economicista predominante em seu caráter abstrato, nas formulações sobre o tema e em sua insuficiência... (p.290-3).

Os trabalhos de Luiz Pereira, e, depois, um pouco mais tarde, os de Luiz Antonio Cunha (1977) e Gaudêncio Frigotto (1984), entre alguns outros, constituíram referenciais importantes na contestação teórica à abordagem economicista da educação e de seus pressupostos. A. Gramsci foi, sem dúvida, ao lado de Marx, o autor mais utilizado, na ocasião, por pesquisadores da temática, no embate tanto contra a teoria do capital humano como às abordagens reprodutivistas ${ }^{7}$.

\footnotetext{
7 . Luiz Pereira (1977:86), por exemplo, considera "importante realçar que, sobretudo com Gramsci, se 'revolucionou' a concepção de superestrutura (dominante), ao distinguir, nela, de maneira sistemática, o aparelho repressivo de Estado e os aparelhos ideológicos de Estado - com isso rompendo, mais do que outros clássicos do materialismo histórico, com a distinção posta pela ideologia liberal: a diferenciação entre Estado e Sociedade Civil em termos da concepção do primeiro como uma instância...".
}

TrabalhoNecessário - www.uff.br/trabalhonecessario; Ano 13, № 20/2015. 


\section{Trabalhonecessário}

Issn: 1808 - 799X

ano 13 , número $20-2015$

\section{O GT Trabalho e Educação}

O referido domínio de pesquisa se consolida, no país, com a formação do GT Trabalho e Educação da ANPED, em 1981.

A opção de utilizar as noções de educação e trabalho e não as de formação e emprego, como é frequentemente utilizado nos meios políticos e empresariais, teve o propósito de questionar as virtudes atribuídas à formação em matéria de resolução dos problemas do emprego, e de apresentar a relação da formação com o emprego como objeto de análise. Problematizar essa relação significava, ao mesmo tempo, definir um método de análise (de interrogação e de explicação) que possibilitasse apreender as tensões e conflitos inerentes à sua constituição (Tanguy, 1998, Moraes, 1999; 2002).

Como já foi mencionado, no que se refere ao desenvolvimento do campo de pesquisa trabalho e educação, às suas orientações teóricas e escolhas temáticas, nas décadas de 1970 e 1980, as possibilidades de enfrentar os obstáculos relativos à análise dos "vínculos" entre educação e trabalho, entre sistema educacional e sistema produtivo, entre escola e mercado/economia, estavam delimitadas pelo predomínio das explicações sociológicas inscritas no quadro das correntes teóricas dominantes entre nós, e que circunscreviam os estudos acadêmicos no período: de um lado, as Teorias da Reprodução e, sobretudo, as da Reprodução Cultural, com a enorme repercussão da análise de Bourdieu e Passeron sobre o sistema educativo, exposto em "A Reprodução"; de outro lado, as teorias econômicas neoclássicas, em particular aquela do "Capital humano", contra as quais se insurgiam criticamente as primeiras. A contundência das críticas às teorias da reprodução foi proporcional à influência dessas formulações na sociologia da educação. A recusa dessa abordagem estritamente estrutural da realidade social e o esforço para superar, na análise, suas insuficiências teóricas marcou a trajetória de diferentes autores nos anos seguintes. 


\section{Trabalhonecessário}

Issn: $1808-799 X$

ano 13, número $20-2015$

Esse quadro de preocupações alimentou a criação do GT. O professor Miguel Arroyo (1981), no seu texto subsídio sobre os rumos investigativos do grupo, apontou três questões orientadoras fundamentais à construção do campo de pesquisa: 1) vínculo entre educação e processo produtivo na política educacional; 2) aprofundamento das relações entre escola e trabalho decorrentes das imposições do capital; 3) a luta pela escola e por um projeto popular de educação como decorrência do movimento de organização da classe trabalhadora.

Tais questões, posteriormente detalhadas em debates promovidos pelo grupo de pesquisa, foram organizadas em uma pauta temática portadora de cinco grandes eixos de investigação: a) trabalho e educação - teoria e história; b) trabalho e educação básica; c) profissionalização e trabalho; d) educação do trabalhador nas relações sociais de produção; e) trabalho e educação nos movimentos sociais.

Estudos sobre a produção do GT têm indicado que conjunto significativo das pesquisas elege a Educação Básica como objeto de investigação, centrandose particularmente no Ensino Médio e na Educação Profissional, incluindo a modalidade de Educação de Jovens e Adultos/EJA, com menor ênfase na Educação Fundamental e na Educação Superior (Kuenzer 1987, 1991; Ciavatta e Trein, 2003; e Klein, 2011).

De acordo com estes mesmos estudos, apesar da vocação pluralista do GT e das crises de paradigmas das últimas décadas, a maioria dos trabalhos utilizam, em suas análises, referenciais teóricos de inspiração marxista/marxiana, ou seja, priorizam, como método de construção do conhecimento, o materialismo histórico dialético. Segundo Klein (2011), as reflexões produzidas pelos pesquisadores do GT da ANPED nos embates econômicos, políticos e educacionais teriam consolidado o grupo "como uma trincheira de resistência aos golpes da reestruturação produtiva e suas formulações ideológicas". 


\section{Trabalhonecessário}

Issn: $1808-799 X$

ano 13 , número $20-2015$

No entanto, atualmente, no que concerne às análises sobre o Ensino Médio e às concepções teóricas que sustentam a formulação de uma proposta de "ensino médio integrado", capaz de superar a sua histórica dualidade organizacional reafirmadora das desigualdades sociais, encontram-se divergências de interpretação bastante sugestivas (mesmo quando alicerçadas nos mesmos autores) que levam a posicionamentos distintos na análise e proposição de políticas públicas para essa etapa educacional.

$\mathrm{Na}$ perspectiva de contribuir para o debate, proponho-me a apresentar algumas reflexões e considerações de método produzidas em minha trajetória de pesquisa no esforço de compreender os processos educativos como processos sociais inclusivos, uma dimensão de outros processos sociais globais imbricados nas formas mais amplas da reprodução e produção social, o que pressupõe, em particular, apreender a complexa relação educação e trabalho.

\section{Algumas considerações sobre a escola e sua relação com o trabalho}

A partir de uma leitura crítica das Teorias da Reprodução propiciada pelas contribuições de Henri Lefebvre, Pierre Naville e Lucie Tanguy, entre alguns outros, desenvolvo, a seguir, algumas considerações à análise da escola e da educação profissional, para, na sequência, discutir a proposta de educação unitária na obra de Gramsci e suas implicações para os projetos de ensino médio e a sua forma integrada.

\section{a) A crítica às teorias da reprodução e suas implicações à análise da relação educação e trabalho ${ }^{8}$}

As teorias da reprodução social, atribuindo centralidade ao trabalho e à produção material, representam a escola como aparelho que preside a

\footnotetext{
${ }^{8}$ As reflexões deste tópico baseiam-se em dois trabalhos da autora: Moraes, 2005 e 2012b.
} 


\section{Trabalhonecessário}

Issn: $1808-799 X$

ano 13, número $20-2015$

distribuição dos agentes sociais no seio da divisão social do trabalho (por meio da distribuição de normas e disposições requeridas por essa divisão), e, contraditoriamente - tal como faz, de forma transversa, a Teoria do Capital Humano - se propõem a mostrar as "correspondências" que se estabelecem entre o sistema educativo e o sistema produtivo em longos períodos.

As Teorias da Reprodução Cultural opõem ao princípio da centralidade das relações de produção o princípio da centralidade da autonomia do aparelho escolar, que agiria na esfera cultural considerada como relativamente autônoma em relação à esfera produtiva. Dessa maneira, mudanças que ocorrem em determinado período ou extensão do aparelho escolar realizam-se segundo suas tendências próprias e podem contrariar aquelas que se desenvolvem no sistema produtivo. Nessa direção, ao afirmarem a "autonomia relativa" das práticas educativas propõem rejeitar não só o postulado da "teoria do reflexo", mas contestar o princípio da correspondência, "sustentando a irredutibilidade dos fenômenos culturais aos econômicos, mesmo quando aqueles encontravam ali seus determinantes" (Tanguy, 1986, p.106).

Por outro lado, afirmando-se como universais nas sociedades capitalistas industriais, essas teorias buscam apreender a organização e o funcionamento do aparelho escolar no seu conjunto, excluindo certas questões relativas aos níveis intermediários do aparelho escolar ou sistema de ensino (Tanguy, 1986, p.107). Ou seja, as teorias privilegiam o estudo de alguns níveis e modalidades de ensino, aqueles do ensino geral, ignorando o setor do ensino técnico, frequentemente representado sob forma negativa: do não geral. Nessa direção, a escola profissional é vista como "lugar de desaculturação/ aculturação, doutrinamento e sujeição" (Grignon, C., 1971).

Como observa Tanguy (1986, p.106), o predomínio destas teorias induziu à formulação de análises sobre o ensino técnico em termos quase exclusivos de dominação cultural e ideológica, deixando de lado questões relevantes relacionadas à especificidade desse tipo de ensino "responsável pela transmissão 


\section{Trabalhonecessário}

Issn: $1808-799 X$

ano 13 , número $20-2015$

de saberes e saber-fazer, direta ou indiretamente úteis em atividades produtivas", isto é, como "um momento no processo de construção da qualificação operária".

Em resumo, estas formulações trazem, a meu ver, elementos fundamentais para contestar tanto as análises lineares da correspondência entre o econômico e o social, como as que definem como única "função" das escolas profissionais a "função" ideológica (de relegação/sujeição/ discriminação) anulando, dessa maneira, a especificidade interna da educação profissional e técnica, como se sua racionalidade fosse determinada unicamente pela organização do trabalho. 0 esforço teórico consiste, então, em estabelecer um duplo movimento: o de apreender tanto o uso que o sistema produtivo faz do ensino profissional, quanto a maneira como essas relações constituem-se no interior da escola, na organização de tipos e modalidades de ensino separados, na divisão hierárquica que introduz entre educação geral e profissional (entre outros aspectos), como nos ensina Pierre Naville (1945).

Subsidiada pela reflexão dos autores citados, entendo que as dificuldades na apreensão do objeto de estudo em questão encontram-se, em primeiro lugar, na recusa de analisar as instituições de ensino profissional nas suas formas e atribuições específicas, o que - conforme Cunha Neves et al. (1983, p.63) indica o predomínio de uma certa concepção de sistema educacional "como sistema fechado, produtor de seus próprios valores, sua própria racionalidade e legitimidade".

Para essas autoras, a divisão historicamente estabelecida entre ensino geral (ou disciplinas gerais) e ensino profissional e técnico, é a divisão que remete à separação radical entre conhecimento puro e conhecimento aplicado. Se o funcionamento institucional dessa divisão no interior do sistema de ensino possui sua própria significação, é preciso analisá-lo, e não basta colocar em evidência a lógica social que the é subjacente quando se pretende questionar os conhecimentos postos em prática no exercício de uma profissão (Cunha Neves et al., 1983, p.63). 


\section{Trabalhonecessário}

Issn: 1808 - 799X

ano 13 , número $20-2015$

Em segundo lugar, tais dificuldades residem no caráter unilateral assumido pelas análises realizadas: se as teorias da reprodução cultural têm contribuído para mostrar o papel central da escola na hierarquia social, elas o fazem na perspectiva da reprodução da ordem social (apreendida em sua globalidade), ignorando a importância do sistema de ensino na produção das hierarquias sociais (e não apenas na sua reprodução). De acordo com Tanguy (1986, p.108), as teorias da reprodução cultural têm "de uma certa maneira desconhecido os fenômenos que alimentam os estudos sobre a mobilidade social", o aparecimento, a regressão ou a extensão de certas categorias socio-profissionais . Tais fenômenos - segundo ela - "são analisados em termos de 'estratégias de reconversão' por Bourdieu (1978), o que o leva a minimizar a importância, a natureza e o significado das mudanças em curso".

Por sua vez, segundo Lefebvre (1973:62), Bourdieu e Passeron, em Les Héritiers e mesmo na Reproduction, ao examinarem apenas o recrutamento do pessoal dirigente na sociedade burguesa, "não vão além, senão incompletamente, da reprodução dos meios de produção, meios de que os agentes da produção fazem parte". A esse respeito, é útil mencionar - enquanto questão de método que a extensa elaboração de Marx sobre a formação do capitalismo, ou seja, sobre a sua gênese e a sua história, pressupõe apenas, como nos indica Lefebvre (1973, p.47) a análise crítica da produção e da reprodução dos meios de produção", das forças produtivas - os próprios trabalhadores e seus instrumentos de trabalho. De acordo como o autor (1973, p.52), a formulação teórica mais acabada do tema encontra-se no "Capítulo Inédito de O Capital" (1984), texto em que Marx apreende as relações sociais como resultado incessantemente renovado do processo de produção. O que significa que a reprodução das relações sociais não se dá sem modificações, que as contradições também se reproduzem e se modificam; antigas relações se dissolvem e outras se constituem, de maneira "que há produção de relações sociais no seio da reprodução" (1973,p.104). Não há reprodução sem produção de novas relações. 


\section{Trabalhonecessário}

Issn: $1808-799 X$

ano 13, número $20-2015$

Ao mesmo tempo, o predomínio do determinismo tecnológico e econômico nas interpretações tem levado a separar a formação profissional da educação geral, submetendo-a unicamente à racionalidade do mercado de trabalho, ocultando um aspecto bem estabelecido pela sociologia: que a escola não pode ser reduzida a instrumento de qualificação e que, em suas atribuições sociais, a escola só participa de modo indireto da construção das qualificações. Isso significa que o ensino técnico, por exemplo, não pode ser visto "em termos de produção de qualificações",

mas enquanto modo de produção e de aquisição de um conjunto de competências técnicas e qualificações sociais que se tornam qualificação no mercado de trabalho, e enquanto representa um modo de socialização das jovens gerações a um espaço de trabalho ou de qualificações hierarquizadas e, mais geralmente, a um espaço sociocultural igualmente hierarquizado (Tanguy, 1986, p.110).

Assim, nessa perspectiva, ao estabelecer as relações possíveis entre sistema educativo e sistema de trabalho, importa reconhecer que estas relações não são diretas, mas se estabelecem a partir de uma longa cadeia de mediações e que é neste nível que deve ser situada a investigação. Portanto, a análise deve recusar tanto as orientações teóricas que entendem ser a formação técnica produto da racionalidade da organização do trabalho ou do sistema tecnológico, como aquelas que, de outro lado, a apreendem como resultado de uma racionalidade estabelecida unicamente no sistema educativo (Tanguy, 1986; Cunha Neves et al., 1983; Moraes,2005, 2012a ).

A esse respeito, também é salutar reafirmar - enquanto questão de método - que o conceito de relação social permite evitar impasses epistemológicos comuns às abordagens estruturalistas e pós-estruturalistas (Pfefferkorn, 2007); que a apreensão do pensamento de Marx no seu movimento, na sua formação (Lefebvre,1974, p.167), por meio da incorporação de momentos dialéticos e/ou noções fundamentais como a de mediação, de interações e, sobretudo das 


\section{Trabalhonecessário}

Issn: 1808 - 799X

ano 13 , número $20-2015$

formas ${ }^{9}$ possibilita questionar/enfrentar a banalização esquemática/ dogmática da "determinação em última instância da base econômica" ou cometer os equívocos da análise funcional/estrutural em relação à escola.

Nessa perspectiva, como procuro enfatizar em meus estudos, não se pode continuar considerando por mais tempo as políticas de educação e formação como respostas do sistema de educação e de formação profissional às necessidades do sistema produtivo, como se tais necessidades surgissem ali espontaneamente, ou como efeito inevitável das mudanças tecnológicas, ou fossem de competência exclusiva dos empregadores. Ao contrário, dialeticamente, elas devem ser vistas como estratégias com consequências no campo da produção, isto é, como opções formativas vinculadas a opções sobre o emprego e a organização do trabalho, que derivam destas e são, por sua vez, um dos instrumentos de sua materialização (Enguita, 1992, Moraes, 1999, 2002).

Após essa digressão sobre a escola básica, a divisão historicamente estabelecida entre ensino geral (ou disciplinas gerais) e ensino profissional e técnico, e sobre o significado do funcionamento institucional dessa divisão hierarquizada no interior do sistema de ensino, passo a comentar:

\section{b) As contribuições de Gramsci e (sua) concepção de escola unitária}

Os esforços analíticos de Gramsci ao lidar com a problemática, posta nos textos de Marx, das relações entre estrutura e superestrutura, de apreender as mediações entre o econômico e as outras dimensões do político e do ideológico (Moraes, 1978, p.73), as tentativas de superar, de um lado, o que considera como "materialismo mecânico ou fatalista" e, de outro, "a concepção voluntarista do

\footnotetext{
9. As relações de produção encerram contradições, nomeadamente as contradições de classe (capital/salário) que se amplificam em contradições sociais (burguesia/proletariado) e políticas (governantes e governados). Estas relações de antagonismo, lembra Lefébvre (1973:48;72), surgem na prática social por meio de formas que as sustentam e mascaram, por exemplo, a forma contratual ( a do "contrato de trabalho" , ficticiamente livre, que liga os membros da classe trabalhadora e os da burguesia, e que pretensamente os associa). Este resultado global compreende, portanto, "as elaborações jurídicas das relações de produção, as relações de propriedade codificadas - as ideologias que 'exprimem' também, dissimulando-as, as relações de antagonismo - as instituições políticas e 'culturais', a ciência etc. ".
}

TrabalhoNecessário - www.uff.br/trabalhonecessario; Ano 13, № 20/2015. 


\title{
Trabalhonecessário
}

Issn: $1808-799 X$

ano 13 , número $20-2015$

processo histórico" (Gramsci, 2000; 1972), constituem referencias relevantes no combate às abordagens economicistas e estruturalistas da educação e seus pressupostos.

No pensamento gramsciano, é possível apreender a produção da ideologia nas sociedades de classe por meio do seu conceito de hegemonia. Em Gramsci, a hegemonia - categoria que inclui a de ideologia, mas não pode ser reduzida a ela - dá conta das relações travadas fora do terreno da produção econômica. A hegemonia é uma "noção eminentemente relacional, além de prática e dinâmica", e, nesse sentido, expressa "um avanço notável diante das definições de ideologia mais ossificadas, escolásticas, encontradas em certas correntes 'vulgares' do marxismo" (Eagleton, T., 1997,p.107).

A hegemonia nunca é uma conquista definitiva, mas tal como observa $R$. Williams (1994,p.202), "tem de ser continuamente renovada, recriada, defendida e modificada". O conceito de hegemonia expande e enriquece a noção de ideologia emprestando-Ihe "um corpo material e um gume político". É com Gramsci que se efetua

\begin{abstract}
"a transição crucial de ideologia como sistema de ideias para ideologia como prática social, vivida, habitual que deve presumivelmente abranger as dimensões inconscientes, inarticuladas da experiência social, além do funcionamento de instituições formais" (Eagleton, T., 1997,p.106-7) ${ }^{10}$.
\end{abstract}

Nesse sentido, diferentemente do marxismo "estruturalista" - para o qual "no estabelecimento da hegemonia (das classes dominantes) implantava-se a transformação no terreno ideológico, historicamente posterior à transformação

\footnotetext{
${ }^{10}$ A teoria da ideologia de Gramsci é produzida no que é conhecido como molde "historicista". Gramsci suspeita, tal como Lukács, de qualquer recurso a um marxismo científico que ignore a natureza prática, política, historicamente relativa da teoria marxista, e compreende essa teoria como expressão da consciência da classe operária revolucionária. Uma ideologia "orgânica" não é simplesmente falsa consciência, mas uma consciência adequada a um estágio específico do desenvolvimento histórico e a um momento político particular. Para ele, o marxismo é simplesmente a forma de consciência histórica adequada ao presente momento e que desaparecerá quando esse momento for ultrapassado (Eagleton, 1997,p.109).
} 


\section{Trabalhonecessário}

Issn: $1808-799 X$

ano 13 , número $20-2015$

econômica possibilitada pelo acesso do político, fundamento da hegemonia" (Cardoso, 1978:74-5) -, com a separação proposta por Gramsci entre coerção e direção (consentimento), a hegemonia passa a incluir a possibilidade de uma reforma intelectual e moral antes do acesso do político. O novo no conceito de hegemonia consiste, pois, na possibilidade de também os grupos dominados desenvolverem a sua direção intelectual e moral apesar de não terem acesso aos meios de direção.

O que, por sua vez, define a forma como é apreendido o problema teórico da relação entre o ideológico e o econômico. A transformação da sociedade preocupação permanente de Gramsci - não se faz apenas no econômico e pelo econômico. Segundo ele, no Caderno 7, parágrafo 24, "apresentar e expor qualquer flutuação da política e da ideologia como uma expressão imediata da infraestrutura deve ser combatida teoricamente como um infantilismo primitivo". E, "a reforma econômica é exatamente o modo concreto através do qual se apresenta toda a reforma intelectual e moral" (Gramsci, 2000, vol. 1, p.238).

A reforma intelectual e moral prévia ao acesso do político abre a possibilidade da "existência de ideologias fora da ideologia dominante" (Cardoso, 1978,p.75), aspecto não menos relevante para a transformação social.

Mas Gramsci não está em busca de um sujeito de classe "puro", pois uma visão de mundo oposta não é para ele "apenas a expressão da consciência proletária". Qualquer movimento revolucionário eficaz deve ser uma complexa aliança de forças, e sua visão do mundo resultará de uma síntese transformadora de seus componentes ideológicos em uma "vontade coletiva" (Eagleton, 1997,p.113) ${ }^{11}$.

\footnotetext{
${ }^{11}$ Gramsci também não postula uma relação direta entre ideologia dominante e classe dominante. O marxismo "estruturalista" tem costumeiramente acusado sua contraparte historicista de não distinguir entre uma classe social dominante e uma determinante - de negligenciar o fato de que uma classe pode exercer o domínio político sobre a base da determinabilidade econômica de outra. Na verdade, como pondera Eagleton (1997,p.113-4), não existe na teoria gramsciana o pressuposto de uma relação ponto a ponto entre classes e ideologias, já que a ideologia dominante resulta em um híbrido de elementos extraídos da experiência de ambas as classes.
}

TrabalhoNecessário - www.uff.br/trabalhonecessario; Ano 13, № 20/2015. 


\section{Trabalhonecessário}

Issn: 1808 - 799X

ano 13 , número $20-2015$

Em síntese, Gramsci rejeita "qualquer redução economicista da ideologia a mero pesadelo da infra-estrutura" ( Eagleton, 1997,p.109). Para ele, ao contrário, as ideologias devem ser vistas como forças ativamente organizadoras que são "psicologicamente" válidas, moldando o terreno no qual os homens e mulheres atuam, lutam e adquirem consciência de suas posições sociais. Em qualquer "bloco histórico", comenta Gramsci no Caderno 7, parágrafo 21, as forças materiais são o "conteúdo" e as ideologias, a "forma" (2000, vol. 1, p. 238).

Essas reflexões de Gramsci foram seminais na elaboração crítica às interpretações econômicas da educação, ao pressuposto da existência de uma vinculação direta entre educação, treinamento e produtividade, de uma correlação entre escolaridade e nível de rendimento/ganho; enfim, para definir que o campo da mediação da prática educacional é o de responder às condições gerais da produção capitalista por oposição ao processo imediato de valorização do capital (Lounay, 1979, p.189). A proposta de organização da escola unitária - tal como apreendi em Gramsci - se dá no âmbito do debate mais amplo sobre a organização da cultura e as atribuições dos intelectuais no processo de construção de uma nova hegemonia.

A conquista da hegemonia, a luta política pela construção de uma "nova ordem intelectual e moral" na vida social, isto é, a construção de uma "unidade política cultural", pelos trabalhadores, por meio da difusão de sua "visão do mundo" no tecido social como um todo, atribui importância estratégica à escola, instituição social. A concepção de escola unitária, que tem o trabalho humano como princípio educativo, será a principal referência teórica contra a visão economicista da educação e seu contraponto organizacional, a escola dual (separação, no nível médio, da escola de ensino geral e as de ensino profissional).

No Caderno 12, parágrafo 1, escrito em 1932, Gramsci propõe a:

[...] escola única inicial de cultura geral, humanística, formativa, que modere justamente o desenvolvimento da capacidade de 


\section{Trabalhonecessário}

Issn: 1808 - 799X

ano 13 , número $20-2015$

trabalhar manualmente (tecnicamente, industrialmente) e o desenvolvimento da capacidade do trabalho intelectual. A partir deste tipo de escola única, através de experiências repetidas de orientação profissional, se passará a uma das escolas especializadas ou ao trabalho produtivo (GRAMSCI, 2007, $1535)^{12}$.

Para ele, a escola deveria fornecer aos jovens uma formação capaz de propiciar-Ihes autonomia intelectual e inserção na vida social:

A escola unitária ou de formação humanística (entendido este termo, humanismo, em sentido amplo e não apenas em sentido tradicional), ou de cultura geral, deveria assumir a tarefa de inserir os jovens na atividade social, depois de tê-los elevado a uma certo grau de maturidade e capacidade para a criação intelectual e prática e a uma certa autonomia na orientação e na iniciativa. (GRAMSCI, 2007, p. 1534).

No mesmo parágrafo 1 do Caderno 12 encontram-se outras indicações sobre a organização da escola:

A escola deveria corresponder ao período representado hoje pelas escolas primárias e médias, reorganizadas não somente no que diz respeito ao método de ensino, mas também no que toca à disposição dos vários graus da carreira escolar. O nível inicial da escola elementar não deveria ultrapassar 3-4 anos e, ao lado do ensino das primeiras noções "instrumentais" da instrução (ler, escrever, fazer contas, geografia, história), deveria desenvolver, sobretudo, a parte relativa aos "direitos e deveres" atualmente negligenciada, isto é, as primeiras noções do Estado e da sociedade, enquanto elementos primordiais de uma nova concepção do mundo que entra em luta contra as concepções determinadas pelos diversos ambientes sociais tradicionais, ou seja, contra as concepções folclóricas.( 2007, p. 1534- 1535).

A proposta de organização da escola unitária nasce em oposição à reforma educacional implementada por Giovanni Gentile, Ministro da Educação do

\footnotetext{
${ }^{12}$ Trata-se de um texto $C$ do Caderno 4, parágrafo 49, pg. 483, escrito entre 1930 e 1932, sem variações significativas de redação. A tradução da edição italiana dos Cadernos é de Deise Rosálio. Sobre isso, ver também Rosálio, D., 2010.
}

TrabalhoNecessário - www.uff.br/trabalhonecessario; Ano 13, № 20/2015. 


\section{Trabalhonecessário}

Issn: $1808-799 X$

ano 13 , número $20-2015$

governo fascista. A Reforma aprofunda a divisão entre formação geral e formação técnica, além de fragmentar e hierarquizar ainda mais o ensino profissional. Como recorda M. Debrun (2001: 260), Gramsci acompanha as discussões pedagógicas que ocorriam no seio do movimento fascista italiano, nas décadas de 1920 e 1930, em torno da "escola unitária de base". As correntes favoráveis à escola unitária foram vencidas, prevalecendo nas reformas de Giovanni Gentili a tendência de "difundir cada vez mais as escolas profissionais especializadas, nas quais o destino do aluno e sua futura atividade são predeterminadas" (Gramsci, 1972 : 118). A posição de Gramsci é, portanto, contrária a essa concepção fascista de organização do ensino profissional (a qual irá inspirar as nossas Leis Orgânicas do Ensino).

De acordo com estudos sobre a organização educacional da Itália fascista realizados por Bahia Horta (2009, p. 60) a escola complementar, criada na Reforma Gentile no bojo da Reforma do Ensino Médio em substituição à antiga escola técnica, dividia-se me três graus - grau preparatório (ensino maternal) com a duração de três anos, grau inferior, também com a duração de três anos, e grau superior, com a duração de dois anos. As classes acima da quinta recebiam o nome de classi integrativi di avviamento professionale.

Segundo o Ministro, era função da escola elementar "preparar os alunos para empregos menores e para a direção de pequenos negócios" (Circolare de 11 de dezembro de 1923, n. 117. Bolletino Uffi ciale Del Ministero della Istruzione Pubblica, n. 59, 31 de Dezembro de 1923, p. 5290). Para o Régio Decreto de 14 de outubro de 1923, n. 2.345, que estabeleceu os programas para o novo ensino médio, esperava-se que o aluno da escola complementar viesse a conhecer "o seu valor e o seu lugar" na sociedade da qual faz parte, e se preparasse "para a vida modesta, mas nem por isto isenta de pesados e difíceis deveres, que ele deverá viver como pessoa e como cidadão". E, conforme o Bolletino Uffi ciale Del Ministero della Istruzione Pubblica, n. 50, de 17 de novembro de 1923, p. 4413, citado por Horta (2009, p.60), enquanto na instrução clássica o conhecimento 


\section{Trabalhonecessário}

Issn: 1808 - 799X

ano 13 , número $20-2015$

deve ser buscado "em seu grau mais elevado", na escola complementar ele deverá ser dado "na medida em que é necessário para ser bom cidadão".

A intenção parece ser diferenciar os trabalhadores manuais dos trabalhadores técnicos, de modo que "a massa operária não se confundisse com a pequena burguesia de empregados menores e pequenos comerciantes" (Jovine, 1980, p. 170).

$\mathrm{Na}$ perspectiva de Gramsci, a formação para o trabalho nas escolas profissionais que se multiplicavam na Itália não constituía uma democratização.

não se deve multiplicar e graduar os tipos de escola profissional, senão criar um tipo único de escola preparatória (elementarmédia) que leve o jovem até o umbral da eleição profissional, formando ao mesmo tempo uma pessoa capaz de pensar, de estudar, de dirigir ou de controlar o que dirige (1972, p.127).

A escola democrática era aquela capaz de promover a formação humanista que contribuísse para a unidade entre teoria e prática e a elevação cultural dos alunos, que possibilitasse a cada cidadão "tornar-se governante" (Gramsci, 1977).

Nessa direção, propõe que a última etapa da escola unitária seja

concebida e organizada como etapa decisiva capaz de criar os valores fundamentais do 'humanismo', e a autodisciplina intelectual e a autonomia moral necessárias à posterior especialização, seja de caráter científico (estudos universitários), seja de caráter imediatamente prático-produtivo (indústria, burocracia, etc.). $\mathrm{O}$ estudo e a aprendizagem dos métodos criativos na ciência e na vida devem começar nesta última etapa da escola e não ser mais um monopólio da universidade, ou deixado ao acaso da vida prática; esta etapa escolar deve contribuir para desenvolver o elemento da responsabilidade autônoma nos indivíduos, deve ser uma escola criativa (1972, p.127). 


\section{Trabalhonecessário}

Issn: $1808-799 X$

ano 13 , número $20-2015$

\section{Considerações finais: a proposta da educação integral}

As concepções de Gramsci podem ser vistas como herdeiras de uma tradição marxista e libertária no campo educacional. Há, no entanto, lacuna sensível nos estudos históricos no que se refere ao desenvolvimento das propostas de educação nos Congressos de Trabalhadores da Primeira Internacional e o seu desdobramento subsequente após a Comuna de Paris, a extinção da Primeira Internacional e a divisão do movimento, o surgimento da II e da III Internacionais, os confrontos políticos enfrentados pelos trabalhadores no final do século XIX e nas primeiras décadas do século XX.

Os historiadores da educação e do trabalho têm centrado suas análises na posição de Marx e dos trabalhadores da Primeira Internacional sobre a questão do ensino politécnico e sua relevância estratégica para o rompimento da divisão e fragmentação do trabalho.

O conceito abstrato de trabalho, o trabalho como valor de troca, é, como sabemos, "essencial à compreensão do movimento histórico" que constitui o desenvolvimento do capitalismo e do assalariado (Schwartz, Y., apud Charlot, B, 2004, p.17). Marx e Engels insistem na necessidade de suprimir a divisão do trabalho, rompendo com os obstáculos ao desenvolvimento integral humano. A falarem da supressão da divisão do trabalho referem-se tanto à divisão social do trabalho como à sua divisão técnica, fruto específico do capitalismo industrial, que subdivide o trabalhador e introduz, pela primeira vez na história, a separação entre concepção e execução do trabalho. Para Marx, a combinação dos estudos teóricos (concernentes principalmente à tecnologia da produção) com a prática do trabalho na fábrica constituiria instrumento fundamental para acirrar as contradições sociais e promover a luta pela superação da divisão do trabalho. É neste sentido que Marx encoraja a AIT a incluir em sua plataforma a reinvindicação por uma formação politécnica para os trabalhadores. 


\section{Trabalhonecessário}

Issn: $1808-799 X$

ano 13 , número $20-2015$

Entretanto, a proposta da educação integral, pouco mencionada nos estudos sobre os debates e resoluções dos Congressos da AIT, mostra que 0 questionamento das atribuições sociais da escola sob o capital é realizado no âmbito da problematização das relações entre educação e trabalho.

Assumindo perspectiva crítica, capaz de complementar e tornar mais clara a concepção de ensino politécnico, a proposta de educação integral, ligada à história do movimento revolucionário do século XIX, colocava-se contrária à existência de dois tipos de instrução - uma 'aprimorada', reservada aos burgueses, e outra, 'simplificada', destinada aos trabalhadores, expressão da dominação de classe -, em defesa de uma educação igualitária que possibilitasse 'o pleno desenvolvimento de todas as capacidades do indivíduo', 'integrando o trabalho manual e o intelectual' (Moraes, Calsavara e Martins, 2012b).

Tal concepção emancipatória de educação, a da construção de uma escola unitária que integrasse formação geral e formação profissional, propunha superar os métodos e organização da escola reprodutora das desigualdades sociais, considerando essencial que o ensino partisse das relações concretas da vida e o trabalho fosse compreendido de forma ampla, criativa e artística. Tais concepções pedagógicas presentes no "Programa de Ensino Integral", elaborado pelo educador Paul Robin, e apresentado nos Congressos da Internacional de Trabalhadores em Lausane (1867) e em Bruxelas (1868), foram aprovadas consensualmente pelos seus participantes (Moraes, Calsavara, Martins 2012b; Santos, L.E dos, 2013).

Apesar dos conflitos entre as diferentes correntes políticas, a concepção de educação integral e igualitária foi assumida como exigência prioritária pela Primeira Internacional, por Bakunin, Proudhon e Marx, e pelas tendências que representavam (Luizetto, 1986; Moraes e al., 2012b.). Pode-se afirmar que, nessa perspectiva educacional, a concepção do trabalho como princípio educativo, aprofundada mais tarde (1932) por Antonio Gramsci (2000), apreende o trabalho não só como conceito abstrato, mas também como experiência concreta, como valor de troca e como valor de uso, ou seja, não apenas como momento de 


\section{Trabalhonecessário}

Issn: $1808-799 X$

ano 13 , número $20-2015$

exploração e de dominação, mas também "como momento de formação e de partilha de uma atividade", "forma de atividade humana" (Charlot, 2004, p. 18); como possibilidade de criação e realização do homem que o exerce, na perspectiva da superação do alheamento e da exploração.

Nesse registro, o trabalho - centro da vida social - aparece, no plano subjetivo, "como pleno desenvolvimento da atividade (pessoal)", como desenvolvimento da individualidade ou como "produção de si"; e no plano coletivo, como "produção da sociedade", ou "produção social da vida", "produção da política" (Pfefferkorn, 2007; Lukacs, 2004; Clot, 1995). A proposta de educação integral que visa o desenvolvimento integral do trabalhador, referendada por Marx, ao apreender o trabalho em sua dupla acepção, valor de uso e valor de troca, permite apreender a escola não só como espaço de reprodução, mas também como produtora de relações novas, inscrevendo a educação em abordagem mais ampla, como atividade humana, como "trabalho" de produção de si, visão que a lógica predominante da educação como valor de troca, como mercadoria, obscurece (Charlot, 2008, p. 16).

Enfim, uma reflexão final: a ampliação/universalização do ensino médio significa escolarizar alunos de novos setores/camadas sociais. E, como consideram Charlot e Reis (2013, p. 72), o que está em disputa na sociedade brasileira é como se realizará essa ampliação, sob qual modelo. Trata-se, em particular, de definir se deve ser um ensino geral, ou se pode ser igualmente técnico e profissional e, "ato contínuo, de saber se existirá uma forma de hierarquia entre os vários tipos de ensino médio". Na mesma direção desses autores, penso que a "lucidez crítica da sociologia" pode contribuir para que a universalização do ensino médio seja igualmente uma democratização.

A escola deve ser considerada, antes de tudo, "como lugar de atividades" (Charlot e Reis, 2013, p.73). Isto é, a atividade específica da escola é a educação, a formação. A escola não é apenas lugar de produção dissimulada das desigualdades, mas é também um dos poucos lugares sociais afirmando a 


\section{Trabalhonecessário}

Issn: 1808 - 799X

ano 13 , número $20-2015$

igualdade das crianças: "uma bela mentira que pode surtir efeitos de 'self-fulfilling prophecy' (profecia autorealizante)", como insiste B. Charlot em seus ensaios.

O maior propósito das análises aqui apresentadas consiste em fazer a crítica das abordagens funcionalistas que tratam o sistema escolar como mera estrutura, esquecendo-se de que os sistemas educativos de cada país, como as demais instituições sociais, são em grande parte resultado das lutas sociais.

Nesse momento em que assistimos a uma grande ofensiva ideológica - na qual o sistema educativo deve adequar-se às necessidades da produção, isto é, satisfazer as demandas da empresa privada, relegando os direitos sociais da população trabalhadora a uma educação pública, laica e de qualidade (prescritos no artigo 205 da Constituição Federal) -, estou convicta de que a construção de uma alternativa emancipatória para a educação pressupõe o enfoque de uma intervenção mais geral na sociedade.

Tal intervenção exige que as reformas educativas apoiem-se em mudanças no trabalho e na esfera política, uma vez que somente o aprofundamento da participação democrática e a ampliação do conteúdo dos empregos (para que se tornem, de fato, qualificantes) consolidarão demandas e comportamentos sociais favoráveis a uma educação formativa. Não podemos esperar que apenas as reformas educativas rompam a perversidade atual da dinâmica social capitalista em direção à nova hegemonia. A política educativa, como afirma Recio (1997, p.47-8), deve ocorrer "integrada ao conjunto das variadas demandas de transformação social, no qual tomem sentido para milhões de pessoas as propostas de educação integrada que alentam os projetos educativos mais interessantes".

\section{Referências Bibliográficas}

ARROYO, Miguel. Educação e Trabalho. In: Reunião Anual da Associação Nacional de Pós-graduação e Pesquisa em Educação. Rio de Janeiro, ANPED 1981.

ALTHUSSER, Louis. Ideologie et appareils idéologiques d'État, In: La Pensée, n. 151. Paris, 1970. 


\section{Trabalhonecessário}

Issn: $1808-799 X$

ano 13 , número $20-2015$

ARROYO, M. G. Trabalho, Educação, Escola, LDB. In: Revista de Educação. Publicação anual da APEOESP, n.4, setembro, p. 4-12, 1989.

BAUDELOT, C. \& ESTABLET, R. . L'École Capitaliste en France. Paris Maspero, 1971

BOURDIEU, P. Les Héritiers. Paris: Ed. De Minuit, 1964.

\& PASSERON, J.C.. La Reproduction. Paris: Ed. De Minuit, 1970.

BOWLES, S. \& GINTIS, H. (1976) Schooling in América: educational reform and the contribution of economic life. New York: Basic Book, 1976.

CÂNDIDO, Antonio. Tendências no desenvolvimento da sociologia da educação. In: FORACCHI \& PEREIRA, Educação e Sociedade. São Paulo: Companhia Editora Nacional, 1972.

CARDOSO, Míriam L.. Ideologia do Desenvolvimento. Brasil: JK-JQ. Rio de Janeiro: Paz e Terra, 1978.

CARNOY, M. , LEVIN, H.. Education, travail et emploi. Unesco. Institut International de planification de l'éducation, 1980. cap. 2.

CHARLOT, B.; REIS, Rosemeire. As relações com os estudos de alunos brasileiros de ensino médio. In: Krawczyk, Nora (org). Sociologia do Ensino Médio. Crítica ao economicismo na política educacional. São Paulo: Cortez, 2014, p.63-92.

CHARLOT, Bernard. A pesquisa educacional entre conhecimentos, políticas e práticas: especialidades e desafios de uma área de saber. In: Revista Brasileira de Educação, vol. 11, n.31, p. 7-18, jan/abr. 2006.

Educação, Trabalho: problemáticas contemporâneas convergentes. Revista Educação, Trabalho \& Cultura, n. 22, 2004, p.9-25.

CLOT, Y. Le travail sans l'homme. Pour une spychologie des milieux de travail et de vie. Paris: La Découverte, 1995.

CUNHA, L.A.. A política educacional no Brasil e a profissionalização no ensino médio. Rio de Janeiro: Eldorado, 1977.

CUNHA NEVES, A., EIDELMAN, J., ZAGFKA, P.. Tendances de la Recherche en Sociologie de l'Éducation en france: 1975 - 1983. Sociologie de l'Éducation. Dix ans de recherches. Recueil de notes de synthèse publiées par la Revue Française de Pédagogie. Collection Education \& Formation. Paris: INRP, 1990. p. 123-138.

DEBRUN, M.. Gramsci. Filosofia, política e bom senso. Campinas: Editora da Unicamp, 2001.

DUBAR, C. Sociétés sans classes ou sans discours de classe? In: Lien social et Politiques, n. 49, 2003

EAGLETON, Terry. Ideologia. São Paulo: Boitempo Editorial, 1997.

ENGUITA, Mariano Fernandez. Educación, formación y empleo. Madrid : Ediciones de la Universidad Complutense, S.A, 1992.

FORACCHI \& PEREIRA (org.). Educação e Sociedade. São Paulo: Companhia Editora Nacional, 1972.

FRIEDMANN, G.. Où va le travail Humain?, Paris: Galimard, 1950.

FRIGOTTO, G.. A produtividade da escola improdutiva. São Paulo: Cortez, Autores Associados, 1984. 


\section{Trabalhonecessário}

Issn: $1808-799 X$

ano 13 , número $20-2015$

GOUVEIA, A. J. (1985). Orientações teórico-metodológicas da Sociologia da Educação no Brasil. FFLCH-USP, mimeo.15 p.

GRAMSCI, Antônio. Quaderni del carcere. Edizione critica di Valetino Gerratana. 3 edizione. Torino: Einaudi, 2007, 4 volumi.

Cadernos do cárcere. Vol. 1 e Vol. 2.; edição e trad. de COUTINHO,

Carlos Nelson. Rio de Janeiro: Civilização Brasileira. 2000.

Los Intelectuales y la Organización de la Cultura, Buenos Aires,

Ediciones Nueva Visión. 1972.

GRIGNON, C.. L' Ordre des choses, les fonctions sociales de l'enseignement techinique. Paris: Minuit, 1971.

GUILBERT, M.; ISAMBER-JAMATI, V.. Formation et carrières professionnelles de 1000 jeunnes de la région parasienne. In: Population. Cap. 2, 1958.

HORTA, José S. B. A educação na Itália fascista: as reformas Gentile (19221923). In: Revista História da Educação, Pelotas, v.12., n.24. jan./abr. 2008, p. 179-223.

A educação na Itália fascista (1922-1945). In: Revista Brasileira de História da Educação, n 19, p. 47-89, jan./abr. 2009

ISAMBERT-JAMATI, V. Éducation et maturité sociale dans la France contemporaine. In: Cahiers internationaux de sociologie. N. 31, Cap 1, 1961.

JOBERT, A, MARRY, C., TANGUY, L.. Éducation et Travail en Grande- Bretagne, Allemagne et Italie. Paris: Armand Colin Éditeur, 1995

JOVINE, Dina Bertoni. La scuola italiana dal 1870 ai giorni nostri. Roma: Editori Riuniti, 1980.

KLEIN, L. R.. A produção do GT Trabalho e Educação e suas interlocuções com a Educação Básica: uma demanda (des)atendida?. In: Ramos, Flávia B.; Paviani, Neire M. S.; Azevedo, Tânia M. (Org.). A Pós-Graduação e suas interlocuções com a Educação Básica: múltiplos olhares. Caxias do Sul - RS: EDUCS/Caxias do Sul / Casa Leiria/São Leopoldo, 2012, v. 1, p. 380-426.

KUENZER, Acácia. Educação e Trabalho no Brasil: o estado da questão. Brasília: Inep, 1987.

LAUNAY, Jean. Éléments pour une Économie Politique de l'Education. In: Economie et Politique, no 184 . Paris, 1969.

LAUTIER, B., TORTAJADA, R.. École, force de travail et salariat, Grenoble: OUG - Maspero, 1978.

LEFEBVRE, Henri . L'ideologie structuraliste. Paris : Anthropos, 1971.

1973. A re-produção das relações de produção. Porto/Portugal: Escorpião,

. Sociologie de Marx. Paris: Presses Universitaires de France/PUF, 1974.

LUIZETTO, Flávio Venâncio. O movimento anarquista em São Paulo: a experiência da Escola Moderna no 1 (1912-1919). Educação e Sociedade,

Campinas, ano VIII, n. 24, p. 18-47, ago. 1986.

LUKÁCS, G. Ontologia del ser social. El Trabajo. Buenos Aires: Herramienta, 2004. 


\section{Trabalhonecessário}

Issn: 1808 - 799X

ano 13 , número $20-2015$

MARX. K. . O Capital. Livro I, CapVI -Inédito. São Paulo: Ciências Humanas, 1978

. El capital. México: Siglo Vientiuno Editores, 1984.

Elementos Fundamentales para la crítica de la Economia Política

(Grundrisse) - 1857-1858. México: Siglo Vientiuno Editores, 1987.

MORAES, Carmen S. V.. Ideologia e Intelectuais em Gramsci. In: Revista Educação e Sociedade, ano I, n 1, set. 1978. Campinas: Faculdade de Educação/UNICAMP e Cortez\&Moraes, 1978.

e OLIVEIRA, Bernadete. A teoria das formas em Lefebvre. In: MARTINS, José de S. Henri Lefebvre e o retorno à dialética. São Paulo: Hucitec., 1994, p.99107.

- Introdução - A relação trabalho-educação e o "novo conceito de produção": algumas considerações iniciais. In: Moraes, CSV e Ferretti, C. (coord.). Diagnóstico da Formação Profissional. Ramo Metalúrgico. São Paulo: CNMCUT/Rede Unitrabalho, Artchip Ed., 1999. p. 15-28.

O ensino técnico, a formação profissional e o mundo do trabalho: algumas questões de método In: Zibas, Aguiar, Bueno (orgs.), O Ensino Médio e a Reforma da Educação Básica. Brasília: Plano Editora, 2002.

. Introdução. Relação trabalho e educação: situando o tema. In: A Relação Trabalho e educação em perspectiva histórica e sociológica. Livre-docência, FEUSP, p. 6-41, 2005.

. A relação trabalho e educação: desafios teóricos na construção de um pensamento crítico. Reunião Anual da ANPED, 2012a.

, CALSAVARA, T., MARTINS, A. M.. O ensino libertário e a relação entre trabalho e educação: algumas reflexões. Revista Educação e Pesquisa, FEUSP, São Paulo, v. 38, n. 04, p. 997-1012, out./dez., 2012b.

NAVILLE, P.. Théoire de lórientation professionnelle. Paris : Gallimard, 1945. . La formation professionnelle et l'école. Paris : PUF, 1948.

. Essai sur la qualification du travail. Paris : Marcel Rivière, 1956.

École et societé. Paris: Rivière, 1959.

PEREIRA, Luiz. Trabalho e Desenvolvimento Social no Brasil. São Paulo: Difel. 1965.

(org.). Desenvolvimento, Trabalho e Educação na América Latina. Rio de Janeiro: Zahar Editores, 1974.

PFEFFERKORN, Roland. Inégalités et rapports sociaux. Rapports de classes, rapports de sexes. Paris: La Dispute, 2007.

POULANTZAS, N.. Les classes sociales dans le capitalisme aujourd'hui. Paris: Le Seuil, 1974.

RECIO, A.. Escuela, economia y trabajo. In: MientrasTanto. Publicacón trimestral de ciencias sociales. Barcelona. n. 68/69, p. 31-48, 1997.

ROSALIO, D. Intelectuais, cultura e escola única no pensamento políticopedagógico de Antonio Gramsci. Dissertação de Mestrado. São Paulo: FEUSP, 2010. 
Issn: $1808-799 X$

ano 13 , número $20-2015$

SANTOS, L. E. dos. Ideias em movimento: a educação libertária e o pensamento pedagógico moderno. Tese de Doutorado. São Paulo: FEUSP, 2013.

SCHULTZ, T. W. . O valor econômico da educação. Rio de Janeiro: Zahar, 1973.

SILVA, G. B.. Introdução à Crítica do Ensino Secundário. Rio de Janeiro: MECCADES, 1959.

. Educação e Desenvolvimento Nacional. mimeo., CRPE (Centro Regional de Pesquisas Educacionais), Fundo: Carlos Mascaro,1965. Centro de Memória da Educação FEUSP - Universidade de São Paulo.

SIMONSEN, M. H. Brasil 2001. Rio de Janeiro: APEC Editora, 1969.

TANGUY, Lucie (dir.). L'introuvable relation formation/emploi. Um état de recherches en France. Paris: La Documentation Française, 1986.

\& MARRY, C. Introduction, La constituition d'un champ de recherche. Tableau économique et social. In: TANGUY, Lucie (dir.) L'introuvable relation formation/emploi. Um état de recherches en France. Paris: La Documentation Française, p.13-33, 1986.

. Pierre Naville, 1942-1960: une sociologie des relations. In: ÉLLIARD, M. (org.), Naville, la passion de la connaissance. Toulouse: Presses Universitaires du Mirail, p. 55-67, 1996.

Genèse d'un espace d'ativité sociale, la formation professionale contiue. Paris: Conseil Scientifique de l'Université Paris X, Nanterre/ Ministère de l'Éducation Nationale, 1998.

TERRAIL, J.-P. et POULLAOUEC,T.. École et divisións sociales. In: BOUFFARTIGUE, P. (dir.). Le retour des classes sociales. Inégalités, dominations, conflits. Paris: La Dispute, 2004.

THOMPSON, E.P. A miséria da teoria ou um planetário de erros. Rio de Janeiro: Zahar editores. 1981.

TREIN, Eunice e CIAVATTA, Maria. O percurso teórico e empírico do GT Trabalho e Educação: uma análise para debate. In: Revista Brasileira de Educação, n.24, p. 140-164, set/dez. 2003.

WILLIANNS, R. . Sociología de la cultura. Barcelona: Ediciones Paidós, 1994.

Recebido em 15 de abril de 2015 Aprovado em 02 de maio de 2015

Errata (conforme enviada pela autora em 12 de maio de 2015)

Pg. 106, final parágrafo inicial, substituir meios de direção por "meios de dominação".

Pg. 109, 1‥ parágrafo, substituir texto original por: De acordo com estudos sobre a organização educacional da Itália fascista realizados por Bahia Horta (2008, p. 198), a escola elementar dividia-se em três graus ... (continua texto original).

No parágrafo seguinte, substituir texto original por: Segundo o Ministro Giovani Gentille, era função da escola complementar criada no bojo da Reforma do Ensino Médio em substituição à antiga escola técnica, "preparar os alunos ... (continua texto original). 